\title{
Revisiting the subculture: understanding deviant student in China
}

\author{
Cheung, C.K.
}

\author{
Liu, L. L
}

\section{Introduction: the social background of the research}

During the three decades since the opening up of China, Chinese society has undergone an acute transformation in terms of rapid economic development, political reform, and diversified social cultures and values brought about by China`s involvement in the trend of globalization.

This has profoundly influenced the new generation of young people. Nowadays, most of them are only-children in urban families (Baker, 1987; Ponston \& Falbo, 1990; Li, 1996; Xiao, 2007). As such, they enjoy creature comforts and more attention from their parents, and probably grandparents as well. In addition, due to the prevalence of internet technology and mass media, young people in China can easily become involved in a global 'youth culture' underpinned by a series of values such as hedonism, consumerism and individualism that may pose a challenge to the orthodox values (Cheng, 1997; Liu \& Lin, 2007).

The new generation of young people were mostly born after the 1990s, and are termed "post-90ers". They are considered to be self-centered and spoiled because of their loose sexual attitudes, bizarre dressing style and lifestyle, which they call "non-mainstream". All these characteristics have further gained them the stigma of being labeled the "beat generation" by adults (Guo, Yang \&Wei, 2011; Wei, 2011). What is more, since the education system in China remains centered around academic achievement and is intolerant to diverse interests and abilities, very often, young people are caught in the middle of the diversity of an increasingly commercialized society and the rigidity of school life. Consequently, they may tend to manifest this conflict of values through misconduct in and out of school. This situation has given rise to a large number of deviant students, whose thought, feeling and behavior are determined by the schools, teachers and parents to be violating the mainstream rules and idea. Nowadays, many teachers in China complain that students are becoming more and more unmanageable, lack the motivation to learn, and have poorer academic achievement and more behavioral problems. This is further illustrated by the rising rate of juvenile delinquency in China. Although the proportion of youth crime among the overall crime rate has declined 46\% from 2006 to 2011, the crime rate of minors (young people under 18) among youth crime is on the rise during the present decade (Guan, 2004; Chen \& Shi, 2013). In 2012, the rate was 22.5\% (Law Yearbook of China, 2013) and there is a growing tendency that the age of delinquent juvenile getting lower (Fang, 2014).

\section{Existing research in the context of China}

In view of this disturbing phenomenon, researchers in China have conducted an array of studies to address this problem. The results of their efforts include a profile of deviant youth and their behavior along with statistic data across the country (Guo, 2002); the pattern of deviant behavior (Zhang, 2001); and possible social and personal variables that associate with deviant behavior (Jin, 2006; Bao et al, 2015). In order to 
explain young people's deviant behavior, many researchers also have incorporated Western theories of deviance such as social disorganization, strain theory, social control and learning theory into their analysis (Liu, 1994; Wong, 1997; Epstein, 2000; Huang, 2005; Liu, 2012).

Although these studies help to provide a broad understanding of youth deviant behavior, few of them really look into the day-to-day lives of these young people and their genuine feelings, and this may be because of the limitations of their research methods. Researchers have predominantly used surveys and self-report questionnaires to collect static data. Therefore, they have failed to give a comprehensive account of the interaction between young people and social structures such as school, family, the dominant culture and the political system. Moreover, their research findings are at risk of stereotyping young people with certain risk factors such as single-parent families, underachieving at school, negative peer influences, which may further stigmatize young people (Griffin, 1993).

In view of this research status quo, the concept of subculture offers a pertinent analytical approach to understand these young people in a socially situated context. It provides the key to understanding deviant behavior as a normal response to the immediate social circumstances (Bennett \&Kahn-Harris, 2004). Following this line, some studies have tried to reveal the culture of specific groups of young people who are recognized as 'violent bullies' in a village (Huang, 2008; Chen, 2010). However, research into deviant young people in urban towns and cities remains scarce. This study thus aims to fill this research gap by revealing a group of deviant students' everyday lives and their subculture.

\section{Rethinking subculture theory}

Western scholars have long studied deviant youth, which has produced a large number of theories. From the 1920s to the 1970s, two famous academic institutions, the Chicago School and the Birmingham Centre of Contemporary Cultural Study (CCCS), have conducted many pioneering studies on youth deviant behaviors and youth culture (e.g. Merton, 1938; Cloward and Ohlin, 1960; Becker, 1963; Thrasher, 1963; Willis, 1977; Hebdige, 1979; Brake, 1985; McRobbie, 1986; Cohen, 1987). This is how the concept of subculture as an analytic model came into being, producing an enormous and influential body of subculture theory.

Since first being coined in the 1940s, the concept of subculture has long been credited for enabling a more holistic and integrated perspective to understand the cohesive systems of social organization. It appeared in the early research of the Chicago School on deviant behavior, such as the aforementioned studies of Cohen (1955) and Cloward and Ohlin (1960). However, the real pervasive use of this concept, as Bennett and Kahn-Harris (2004) observe, started with the publication of CCCS' ground-breaking work, Resistance through Rituals (Hall \& Jefferson, 2006). Since then, the concept of subculture has dominated studies of youth, style, music and leisure in the related fields of sociology and cultural studies for nearly two decades. However, the prevalent conceptualization of subculture has been disputed due to several limitations.

First, according to CCCS's argument, young people's cultural manifestations are 
predominately considered as strategies of working-class youth in resisting the dominant culture that marginalizes them. However, this preoccupation with 'class' has been considered an 'oversimplistic model' (Bennett and Kahn-Harris, 2004) and 'theoretical conjecture rather than proven fact' (Muggleton, 2000). It thus underestimates other structural divisions such as gender, race, ethnicity and so forth. The earliest challenge can be traced back to McRobbie and Garber`s (2006) well-known critique of the 'absence of girls'. With the development of post-subculture theory, many researchers have even argued that in a post-industrialized society, a 'supermarket of style' (Polhemus, 1998) has emerged and young people from different social classes, and of different genders and races can often embrace the same style.

Second, the notion of a youth subculture distinct from mainstream culture puts a skewed focus on the spectacular culture patterns of post-war working-class youth such as Teddy Boys, Punk and so on, while ignoring the mundane practices of other young people. Moreover, the romanticization and dramatization of youth subcultures obscure the fact that it is also true that there are many teenagers just playing their subculture roles for fun without a deep commitment to a fixed style (Muggleton \& Weinzierl, 2003).

By the same token, as Chaney (2004) argues, since contemporary culture around the world has become more diverse and is undergoing a process of fragmentation, the distinction between a 'sub' and a 'dominant' culture has become blurred. Therefore, the previous conceptualization of subculture as exclusively distinct from mainstream culture may become irrelevant.

To sum up, the major problem of existing subculture theory, with the view of CCCS being the most prominent, is its excessive concentration on symbolic aspects of youth culture at the expense of the real world of young people and the actual meaning of their subculture. The solutions may be first, to return to the previously abandoned tradition of the Chicago School, which continues to try to understand young people's subculture in specific localities and communities (Bennett, 1999); and second, to develop a re-conceptualization of subculture.

\section{Contextualizing subculture theory in China: methodology and data}

In this study, I undertook an ethnographic study to follow a group of deviant students for eight months, trying to understand their everyday lives and the process of their identity construction. The research was conducted in Xiamen, a coastal city located in the Southeast part of Mainland China. Unlike large metropolitan areas such as Beijing and Shanghai, where most studies have been conducted so far, Xiamen represents one of the medium-sized cities, which are the majority in China.

After a process of sampling among 11 classes from 5 schools in different tiers, I chose one class in Grade 2 at a medium-level secondary school called 'Central Park Secondary School' as a pseudonym. I stayed in the field from March to November in 2009, which was from the second semester of Grade 2 to the end of the first semester of Grade 3. After the main study, I also paid another visit to the school in January and May respectively to follow up on students' recent development. 
The research methods adopted were mainly participant observations and interviews, the latter including both a group and an individual interview. I took field notes on a daily basis. In order to complement and triangulate the data gathered, the interview questions emerged from observation and informal communication. I enquired about the participants' life history, career aspirations, deviant behavior and their families. All the individual and group interviews were tape-recorded and transcribed verbatim.

From the start, my role was a practice teacher who was doing her research on student culture at the same time. I tutored students who had difficulties in mathematics and Chinese in a supplementary classroom during a self-study session in the last lesson of the day. When they became familiar with me, students in the class started to treat me as their friend. This meant that I was able to gain access to their little secrets and anecdotes. We were also able to make fun of each other in a friendly way. Since there were many batches of practice teachers coming to the school, students had already developed a strategy to deal with adults like me. Just like my participants said: "At school, you're our teacher, but once we pass through the school gate, you're not; we'll treat you like a friend." They also suggested that I should not tell anyone what they did outside school.

During my observation in the class, I identified 6 students who were often scolded by their teacher for their disturbing behavior. Most of them were assigned seats in the back corner of the class so as to minimize their disruption or their negative influence on the class. These students spontaneously formed a subgroup in the class and hung out together almost all the time. They had been designated as problem students by teachers, and their subgroup was called " $5+1$ " in public. However, I later found one student among them who was not a typical problem student and did not even belong to their group. This was also confirmed by the response from the other students as no one knew his phone number and QQ (the most popular free instant messaging software in mainland China), which were their main means to contact each other. Besides, the teacher also suggested excluding him from the group because "he is doing ok now". Therefore, five students were finally chosen as participants of my study. Informed consent was obtained from them and their parents. In this study, I called this group, ' $4+1$ ' youths. Since I had more time to spend time with the ' $4+1$ ' youths, they usually addressed me as their sister. However, it is worth noting that in their terminology, sister or brother was more like a term used to address friends who were older. Most of the time they were not sisters or brothers by blood as most children in cities are the only child in the family. This appellation also implies that they eagerly needed some relationship of sisterhood or brotherhood.

Table 1 presents a general profile of the families of the ' $4+1$ ' youths':

First, all the '4+1' youths were from lower-class families. Following Lu's (2004) classification of social strata in China in the post-reform era, the ' $4+1$ ' youths' families fell into the lower strata. This further indicates that they had very few economic, institutional and culture resources. According to the Statistics Bureau of Siming District (2011), the per capita per month disposable income (PDI) in Siming district is $¥ 2911$ (around U.S.\$350). From the above table, the average PDI of the ' $4+1$ ' youths' families is below $¥ 2000$.

Second, their parents' education level was relatively low, which meant that the parents 
not only were unable to help their children with their school work, but also, as existing research has effectively pointed out, were prone to adopt inappropriate parenting styles (Laser, Luster, \& Oshio, 2007; Park, Kim, \& Cho, 2008).

Third, all the ' $4+1$ ' youths were from one-child families. As previously discussed, the new generation of young people only-children produced by the one-child policy can enjoy more attention and creature comforts from their families. This further helps them to gain the upper hand in confrontations with their parents. By the same token, even though the ' $4+1$ ' youths were from economically deprived families in the urban area, they still had weekly pocket money and annually 'red-envelopes'. More money at their disposal meant more choices for their leisure-time entertainment and a larger scope of activity. This of course did not necessarily have a negative impact on the young people, but when taken into consideration with an ineffective parenting style, it surely undermined the family control over these young people.

Among their group, Onion was the leader. He was well-known for his toughness and personal loyalty, and also for the smart way he dealt with teachers. Most of the time, the confrontation between problem students and teachers would lead to disaster, but in Onion`s case, he managed to claim his right without overstepping the mark, and his ability was also admired by other boys, not only inside the group, but also in the whole grade. Dusk was the only girl in the group. She was very active and arranged most of the group gatherings. She also had a big network in the community including students, new graduates and drop-outs. Shanji and WS were followers of Onion. The three lived near to each other and thus stuck together almost all the time. As for XXL, his situation was a bit complicated. He was always teased by the other four for his conceit and rudeness; as they put it, he "doesn't know how to act like a man". This drove him closer to another group at school, whose leader was hierarchically under Onion in the whole structure of the gang they belonged to.

The following diagram sketches their relationship:

Figure 1 inserted here

It is noteworthy that this group was not a closed group and was always undergoing changes, incorporating other elements through interaction with other students, gang members and the wider society. That is why the symbol of a multi-point star was chosen to stand for their social relationships outside the group. Each of them had established their own social network, and their network outside the group was also interconnected. During the study, their interaction with other gang members and their social relationships were also taken into account in order to understand their subculture in a more holistic and comprehensive way.

The spectrum of their deviant behavior included: 1) school-based misconduct (i.e. acting up, cutting classes); 2) anti-social behavior (i.e. vandalism, bullying); and 3) offenses (i.e. drinking, smoking, using foul language). According to the interviews with them and the teachers, it was easy to identify a common trajectory of them becoming deviant, and for all of them except for Dusk, this happened as early as their elementary years. From the beginning, they gradually fell behind other students in the class due to various causes, and they started to redirect their energy to other outlets, 
such as misconduct in and out of school, and they were caught out. After being labeled by teachers as deviant students, they began to accept it as part of their identity.

\section{The elements of subculture}

During the 8-month-period in their company, I found that a word they frequently used when describing their lifestyle was 'muddling through' (hun in Chinese). Therefore, this term was used to refer to their subculture. Generally speaking, it means both one`s actions and one`s attitudes in trying to survive in a system or systems without making too much effort or fully performing one's role. Even normal people sometimes describe their lifestyle as 'muddling through' without too much negative connotation. However, when one is involved in some illicit business such as gambling and fighting and so forth, and particularly lives on them, one will be called a 'hooligan'. To the ' $4+1$ ' youths, this subculture was multi-faceted.

\section{Muddling through schooling}

All these 4-1 students tended to undervalue academic achievement. The reason they stayed at school was to obtain the diploma so that they could apply for vocational school or find a job after graduation. A social ethos that favors quick success and instant benefit made them believe that the status success depends on one's "good fortune", no matter how you achieve it, and this does not necessarily depend on good marks. Especially when they considered the massive unemployment of college graduates and even students with postgraduate degrees, they gradually realized that such an investment in effort could not always bring rewards (Liu, 2008), which further fueled this negative perception of the value of education. As WS said, "education is useless. Just like you, you don't even know whether you will get a job after graduation. Why should I bother about my academic performance?"

This low expectation regarding education led to their poor performance at school. They rarely finished the homework. Onion, WS and Shanji were always late for school, and Dusk even cut the morning classes. Besides this, almost every day during all the classes, Shanji, Onion and Dusk slept, XXL read romantic novels and SW played with his mobile phone. They were usually absent from the morning exercise, hiding in the toilet to smoke. This behavior sometimes provoked conflict with teachers.

\section{Muddling through the days}

Most days, they were carefree and only thought about having fun with their friends. There is a tea house located in a comparatively devious place near the school, which the teachers did not know about. In order to cater for students, the owners, a young couple, sold low price beverages, furnished the house with a cozy sofa and a set of hi-fi playing students' favorite pop music all the time. Therefore, it soon became the problem students' hot spot. They gathered there to smoke, play poker games or just to chat until dinner time. Besides this, their entertainment includes going to the billiard room, karaoke box, internet bar and barbecue booth in the street where they could get cheap food and beer. It is interesting that although there is a regulation that commercial entertainment places such as billiard rooms, karaoke boxes and internet bars are forbidden to serve young people under 18, none of my participant was 
rejected and they even went to the billiard room in their school uniforms.

\section{Muddling in the gang}

Gang affiliation was a significant characteristic of their subculture. The gang members usually recruited new blood from secondary schools or even elementary schools, and the notorious problem students in each school are the most tangible ones. However, the new recruits were fully aware that they were just at the bottom of the whole network and thus, they could only be called 'tearaways' (xiaohunhun in Chinese). Even so, they proudly claimed that they knew everyone who was 'muddling in the gangs' in all the schools in the district, which consisted of more than 6 schools. Their involvement in the gang represented a high level of trust and reciprocity. When they were recruited to a gang fight, they just went without asking the reason, because "it's embarrassing to turn them down. Besides, I may ask for a favor in return next time" (Dusk).

\section{Muddling-through identity}

From the foregoing description of the ' $4+1$ ' youths' subculture, we can see that during the process of their hanging out together, they had collectively developed the same behavioral pattern and symbols, and this further gave them a sense of group identity and belonging. In an individual interview with Dusk, she claimed bluntly that they were 'bad kids'. In response to my probing about the difference between 'good kids' and 'bad kids', she answered:

Dusk: Kids like Nina, are good. Eugene is also counted as a good kid. As for kids like us, sitting in the last row, we are bad.

LL: Really?

Dusk: Anyway, we are not good students.

LL: Can you give me some criteria?

Dusk: Well, playing outside, like Onion, Shanji, WS and XXL.

LL: Talking about playing, Eugene also plays a lot.

Dusk: Not that kind of playing.

Clearly, the way of playing outside, although different from the way conformist students' played, was what they call 'muddling'. During the group interview, I asked the ' $4+1$ ' youths the connotation of 'muddling' to them, and they defined it as follows:

WS: Smoking, drinking, fighting, picking up hot chicks.

Onion: Not only this. In short, do whatever things that are not supposed to be done by students, things that the school forbids.

Shanji: Well, I don't think so.

WS: Me either. It's just a narrow definition.

Shanji: Yep, let the teachers know we are critical of them, that's it. Actually, there are many meanings for 'muddling' and the other one is to know young people in the society, hang out with them, go fighting. Be a little 'muddler'.

WS: To state it in a positive sense, 'muddling' means you make friends with people in the society and when you're in trouble, they can help.

From their interpretation, there are many characteristics of this 'muddling-through' 
subculture, from which a 'muddling-through' identity is formed.

\section{Dare to resist}

' $4+1$ ' youths appreciate very much the courage to resist authorities such as school administrators, teachers, parents or even gang members in the higher rank. As a matter of fact, the possession and demonstration of the 'spirit of resistance' was a fundamental criterion with which ' $4+1$ ' youths identified with each other at the initial stage and decided the pecking order among members. As a result, Onion was considered as the big brother among them for his courage to oppose and negotiate with authorities on many occasions. In contrast, XXL was often teased by the others for his reluctance to break loose from his parents' control. However, only resistance with certain characteristics was accepted as the 'right' kind: the kind that can achieve some desirable ends, or at least cause little harm to the demonstrator; otherwise, it was merely a vain attempt, and the actor would be teased by the others. This resistance can be called pragmatic resistance. It relies significantly on good social skills.

\section{Good social skills}

A good inter-personal relationship was considered by ' $4+1$ ' youths as a requirement to 'muddling-through' in both the school and social contexts. It was crucial to them for several purposes- to avoid trouble, to get along well with others and to make a truce with the authorities. WS claimed that his case was the most evident one to illustrate the importance of good social skills. A conceited and ill-tempered student he used to be, WS almost slapped a teacher's face during a confrontation in Grade 7. This incident made him a notorious student in teachers' eyes. But, beginning in the second semester of Grade 8, he gradually changed his behavior by closely observing how Onion interacted with others. Even the teacher in the above mentioned confrontation started to change her view of him. Therefore, through observing others act and the results, the ' $4+1$ ' youths learned from each other to improve their social skills, which to some extend played a positive role in facilitating their coping in the school.

\section{Smoking and drinking}

These two status-offense misconducts have been widely perceived to be attributed to peer pressure in many studies (Chung \& Steinberg, 2006; Dodge et. al., 2006; Tam et. al., 2007; Stewart, 2008). True as it was in the '4+1' youths' case to some extent, smoking to the ' $4+1$ ' youths also served to facilitate their passing through a great symbolic barrier erected against the normative school culture and 'good kids'. This finding is similar to Willis' (2006) research on the role of the drug use of hippies. More interestingly, young people are not as vulnerable as we thought to the temptation of smoking and drinking, or even drugs. Instead, they are fully aware of the harm of alcohol and nicotine and have weighed the pros and cons before taking up some habit. In order to gain the membership of a group that offered them a sense of belonging and meaning, the ' $4+1$ ' youths accepted that their behavior might compromise their health as long as it would not cause irreversible harm.

\section{The relationship with 'parent' culture and agency}

It is widely supported by the classic argument in the subculture literature that youth 
subculture always bears imprints from the 'parent' culture it is derived from; and it is evident that these imprints usually are reflections of social structure such as class, race, gender etc. (Hebdige, 1979). In the same light, '4+1' youths' 'muddling-through' lifestyle was deeply rooted in the lower-class culture of their parents in the forms of several 'focal concerns' downplaying the value of education; the obsession with monetary success; a high tolerance of drinking, smoking, and violence. Moreover, all these 'focal concerns' can be traced back to the mainstream Chinese culture and contemporary social ethos such as the pragmatic view of education; a liberal attitude towards drinking and smoking and so on.

However, no matter how profound and encompassing the influence of the class culture and dominant culture is, the agency of individuals should not be ignored, and very often, this is demonstrated through the subculture they form. Although it is argued that youth subculture is merely 'magical solution' to the problem they encounter (Hall \& Jefferson, 2006; Cohen, 1997) and always results in self-defeating situations and social reproduction (Willis, 1977), I contend that young people's subculture, despite its limitations, always has constructive and positive meanings. In the case of the ' $4+1$ ' youths, their agency can be understood in two aspects subcultural capital and social capital. First, through establishing the 'muddling-through' subculture, which made them distinctive from other students, the ' $4+1$ ' youths possessed more power to negotiate with the school and teachers on issues such as workload and discipline, and with adults for more social space. In addition, the subculture also acted as a safeguard for their psychological wellbeing against overwhelming frustration and strain from the social reality. Second, after a re-conceptualization of social capital to acknowledge young people's special situation and potential (Schaefer \& Nicole, 2004; Holland et. al., 2007; Leonard, 2008), the ' $4+1$ ' youths' social capital can be recognized in terms of the extensive social network they built among students and adults; and the material resources and worldly knowledge they gained from this social network. For example, they were easily able to make friends with adults such as the practice teacher, the school security guard, the grocery store owner, and the cafe owner, who could give them extra resources in and out of school.

\section{Conclusion and discussion}

In this study, a group of problem students identified with each other shared the same problems and situation, and collectively formed a subcultural group, with which they could challenge the authority of teachers and parents; negotiate power in the school, for example reach a truce with teacher so that they could have an easy time at school until they graduated. Their subculture and resistance may seem like a self-defeating practice, because what they learnt at school and the qualification they obtained could only assure them laboring jobs and reproduce their lower class status. However, at least this subculture offered an alternative way to safeguard their happiness and healthy development, which in this case are psychological well-being and a better inter-personal skill.

The concept of subculture used in this study is consistent with the widely-accepted definition that "Subcultures are groups of people that have something in common with each other (i.e. they share a problem, an interest, a practice) which distinguishes them in a significant way from the members of other social groups" (Gelder \& Thornton, 
1996, p. 1). This illustrates that the Chicago-School-origin conceptualization of subculture is still applicable in the understanding of young people in contemporary China. However, as previously mentioned, in much of the subculture literature the subculture always refers to one specific kind of behavior or group, such as skin-heads, night club youth, marijuana users and so on. By taking a close look at the ' $4+1$ ' youths' behaviors and lifestyle, we find in this context, that subculture is rather discursive. They are not restricted to one specific type of behavior, rather, behaviors such as playing billiards, hanging out in pubs, playing pc games, gang affiliation and so forth. All have played if not an equal, at least an important part in their everyday lives and finally constitute a lifestyle which is unacceptable to the mainstream. Therefore, some considerations of the connotation of subculture should be needed.

First, a subculture may consist of different cultural elements such as style, values, ideologies and lifestyle. These elements may come from a quite distinctive matrix, and are sometimes even mutually exclusive, which means that young people's subculture does not necessarily break away from the dominant culture or its 'parent' culture (in this case, lower-class culture in particular). As a matter of fact, young people's subculture is a bricolage, which on one hand, displays their ability and creativity, and on the other, is 'closely intertwined with family histories, gender, place, class, region and locality' (Nayak, 2003, p. 320).

Second, a subculture should always be seen as a process of young people's construction of their cultural identity rather than a static piece of text waiting for analysis. It is always changing with their creators and growing with them. Likewise, the membership of a certain subculture is fluid rather than fixed. Young people can always enter or withdraw at their will.

Last, although in post-subcultural theory, there are many new terms replacing 'subculture', among which 'lifestyle' is widely adopted (Reimer, 1995; Miles, 2000; Featherstone, 2007), the concept of 'subculture' is more relevant in my research context because it emphasizes the aspect that it is a collective construction by a group of young people (Brake, 1985), whereas the post-subcultural construction of alternatives to subculture is apt to interpret young people's lives in an individualistic light.

\section{References:}

Bao, Z., Li, D., Zhang, W., \& Wang, Y. (2015). School climate and delinquency among Chinese adolescents: analyses of effortful control as a moderator and deviant peer affiliation as a mediator. Journal of Abnormal Child Psychology, 43(1), 81-93. doi: 10.1007/s10802-014-9903-8

Becker, H. S. (1963). Outsiders: studies in the sociology of deviance. New York: Free Press.

Brake, M. (1985). Comparative youth culture: the sociology of youth cultures and youth subcultures in America, Britain and Canada. London: Routledge \& Kegan Paul.

Bennett, A. (1999). Subcultures or neo-tribes? Rethinking the relationship between 
youth, style and musical taste. Sociology, 33(3), 599-617.

Bennett, A., \& Kahn-Harris, K. (2004). After subculture: critical studies in contemporary youth culture. Houndmills, Basingstoke, Hampshire; New York: Palgrave Macmillan.

Cohen, S. (1987). Folk devils and moral panics: the creation of the mods and rockers (ed.) Oxford: Blackwell.

Cohen, P. (1997). Rethinking the youth question: education, labour, and cultural studies. Basingstoke, Hampshire: Macmillan Press.

Chaney, D. (2004). Fragmented culture and subcultures. In A. Bennett \& K. Kahn-Harris (Eds.), After subculture : critical studies in contemporary youth culture. (pp. 36-48). Houndmills, Basingstoke, Hampshire ; New York: Palgrave Macmillan.

Chung, H. L., \& Steinberg, L. (2006). Relations between neighborhood factors, parenting behaviors, peer deviance, and delinquency among serious juvenile offenders. Developmental Psychology, 42(2), 319-331.

Chen, B. F. (2010). (in Chinese) Village Bullies in Lianghu Plain: Structure and stratification: Take G Town in Hubei Province as an example. Youth Studies, 370(1), $1-13$.

Chen, W., \& Shi, T. (2013). Jiating yinsu dui weichengnianren fanzui de yingxiang ji duice shizhengyanjiu (Empirical study on the impacts of family factor on juvenile delinquency and solution: A case study in Chongqing). Issues on Juvenile Delinquency, 5, 46-52.

Dodge, K. A., Dishion, T. J., \& Lansford, J. E. (Eds.). (2006). Deviant peer influences in programs for youth:problems and solutions. New York :Guilford Press.

Epstein, I. (2000). Juvenile delinquency and reformatory education in China: A retrospective. In Liu, J., Ross, H. A., \& Kelly, D. P. (Eds.). (2000). The ethnographic eye: interpretive studies of education in China. New York: Falmer Press, 73-6.Fang, M. J. (2014). Lun qingshaonian fanzui zonghe yufang jizhi zhi jiangou (The construction of youth crime prevention system). Youth Exploration, 6, 84-9.

Gelder, K., \& Thornton, S. (Eds.). (1996). The Subcultures reader. New York; London: Routledge.

Griffin, C. (1993). Representations of youth: the study of youth and adolescence in Britain and America. Cambridge [England]: Polity Press.

Guan, Y. (2004). (in Chinese) Concerning minor, family and city: a sociological perspective of youth crime. Youth Studies, 8, 7-11.

Guo, X. (2002). (in Chinese)Youth Deviant Behavior and Prevention. Youth Studies, 5, $50-54$. 
Guo, Z., Yang, P., \& Wei, W. (2011). (in Chinese) Do Not Frown When You See Post-90s. Chinese Education \& Society, 44(2/3), 65-69.

Hebdige, D. (1979). Subculture : the meaning of style. London: Methuen.

Holland, J., Reynolds, T., \& Weller, S. (2007). Transitions, Networks and Communities: The Significance of Social Capital in the Lives of Children and Young People. Journal of Youth Studies, 10(1), 97 - 116.

Huang, H. (2005) (in Chinese) Understanding youth around corner: A perspective of sociology of deviance and Subculture. Youth studies, 2, 43-8.

Huang, H. (2008). (in Chinese) Deviant and mediation of village 'muddlers': an empirical analysis of deviant youth in H Town in Hunan. Chinese Youth Studies, , 13-16.

Hall, S., \& Jefferson, T. (Eds.). (2006). Resistance through rituals: youth subcultures in post-war Britain (2nd ed.). London; New York: Routledge.

Jin, B. H. (2006). Youth criminal and social remedy: a case study of youth. Youth Research,24-30.

Laser, J. A., Luster, T., \& Oshio, T. (2007). Promotive and Risk Factors Related To Deviant Behavior in Japanese Youth. Criminal Justice And Behavior, 34(11), 1463-1480.Law Yearbook of China. (2013). Beijing: China Law Society.

Liu, F. (2008). Constructing the autonomous middle-class self in today's China: the case of young-adult only-children university students. Journal of Youth Studies, 11(2), 193-212.

Liu, R. X., \& Lin, W. (2007). Delinquency Among Chinese Adolescents: Modeling Sources of Frustration and Gender Differences. Deviant Behavior, 28(5), 409 - 432.

Liu, R. X. (2012). The Effects of Strain and Centrality of Strain on Delinquency among Chinese Adolescents*. Sociological Inquiry, 82(4), 578-600. doi: 10.1111/j.1475-682X.2012.00427.x

Leonard, M. (2008). Social and Subcultural Capital Among Teenagers in Northern Ireland. Youth \& Society, 40(2), 224-244.

Miles, S. (2000). Youth lifestyles in a changing world. Buckingham ; Philadelphia: Open University Press.

Muggleton, D. (2000). Inside subculture: the postmodern meaning of style. Oxford: Berg.

McRobbie, A., \& Garber, J. (2006). In S. Hall, \& Jefferson, T. (Ed.), Resistance through rituals: youth subcultures in post-war Britain (2nd ed., pp. 178-188). London ; New York: Routledge.

Merton, R. K. (1938). Social structure and anomie. In Cote, S. (Ed.). (2002). Criminological theories: bridging the past to the future. Thousand Oaks: Sage 
Publications, 96-103.

McRobbie, A. (1986). Postrnodernism and Popular Culture. Journal of Communication Inquiry, 10(2), 108-116.

Muggleton, D., \& Weinzierl, R. (Eds.). (2003). The Post-subcultures reader. Oxford; New York: Berg.

Nayak, A. (2003). 'Ivory Lives': economic restructuring and the making of whiteness in a post-industrial community. European Journal of Cultural Studies, 6(3), 305-325.

Park, S. K., Kim, J. Y., \& Cho, C. B. (2008). Prevalence of internet addiction and correlations with family factors among south korean adolescents. Adolescence, 43(172), 895-909.

Polhemus, T. (1998). In the supermarket of style. In S. Redhead, D. Wynne \& J. O'Connor (Eds.), The Clubcultures reader: readings in popular cultural studies. Oxford, U.K.; Malden, Mass: Blackwell Publisher.

Reimer, B. (1995). Youth and modern lifestyles. In J. Fornäs \& G. Bolin (Eds.), Youth culture in late modernity. London: Sage.

Schaefer, M., \& Nicole, J. (2004). Conceptualizing Social Capital among Young People: Toward a New Theory. Children, Youth and Environments, 14(1), 140-150.

Stahl, G. (2004). 'It's like Canada reduced': setting the scene in Montreal. In A. Bennett \& K. Kahn-Harris (Eds.), After subculture:critical studies in contemporary youth culture. (pp. 51-64). Houndmills, Basingstoke, Hampshire ; New York: Palgrave Macmillan.

Stewart, E. B. (2008). School Structural Characteristics, Student Effort, Peer Associations, and Parental Involvement. Education and Urban Society, 40(2), 179-204.

Tam, K. Y., Heng, M. A., \& Bullock, L. M. (2007). What Provokes Young People to Get into Trouble: Singapore Stories. Preventing School Failure, 51(2), 13-17.

Wei, Z. (2011). (in Chinese)The War between Two Labels. Chinese Education \& Society, 44(2/3), 70-75.

Willis, P. E. (1977). Learning to labour: how working class kids get working class jobs. Farnborough, Eng.: Saxon House.

Willis, P. E. (2006). The cultural meaning of drug use. In S. Hall \& T. Jefferson (Eds.), Resistance through rituals: youth subcultures in post-war Britain (2nd ed., pp. 88-99). London ; New York: Routledge.

Zhang, F. (2001). (in Chinese) Characteristic and Cause of Deviant Behavior in Contemporary Youth. School Journal of Kunming Normal School, 23(2),67-70. 
Table1. Profile of ' $4+1$ ' youths' families

\begin{tabular}{|c|c|c|c|c|c|}
\hline \multirow{2}{*}{$\begin{array}{l}\text { Family } \\
\text { Profile }\end{array}$} & \multicolumn{2}{|l|}{ Parents' job } & \multirow{2}{*}{$\begin{array}{l}\text { Highest } \\
\text { education } \\
\text { level of } \\
\text { parents }\end{array}$} & \multirow{2}{*}{$\begin{array}{l}\text { House-hold } \\
\text { income } \\
\text { (monthly) }\end{array}$} & \multirow{2}{*}{$\begin{array}{l}\text { Housing } \\
\text { condition }\end{array}$} \\
\hline & Father & Mother & & & \\
\hline Onion & $\begin{array}{l}\text { Provisional } \\
\text { construction } \\
\text { worker }\end{array}$ & $\begin{array}{l}\text { Nursing } \\
\text { worker }\end{array}$ & $\begin{array}{l}\text { Primary } \\
\text { school }\end{array}$ & 4000 & $\begin{array}{l}\text { Old tenement } \\
\text { house in the } \\
\text { inner city }\end{array}$ \\
\hline Shanji & $\begin{array}{l}\text { Provisional } \\
\text { construction } \\
\text { worker }\end{array}$ & Saleslady & $\begin{array}{l}\text { Primary } \\
\text { school }\end{array}$ & 3000 & $\begin{array}{l}\text { Slum house in } \\
\text { the inner city }\end{array}$ \\
\hline WS & Driver & Housewife & $\begin{array}{l}\text { Primary } \\
\text { school }\end{array}$ & 4000 & $\begin{array}{l}\text { Old tenement } \\
\text { house in the } \\
\text { inner city }\end{array}$ \\
\hline XXL & $\begin{array}{l}\text { Residential } \\
\text { construction } \\
\text { foreman }\end{array}$ & Laundress & $\begin{array}{l}\text { Primary } \\
\text { school }\end{array}$ & 5000 & Relocation house \\
\hline Dusk & Driver & $\begin{array}{l}\text { Company } \\
\text { driver }\end{array}$ & $\begin{array}{l}\text { Middle } \\
\text { school }\end{array}$ & 6000 & Relocation house \\
\hline
\end{tabular}

Figure 1 Relationship among the ' $4+1$ ' youths

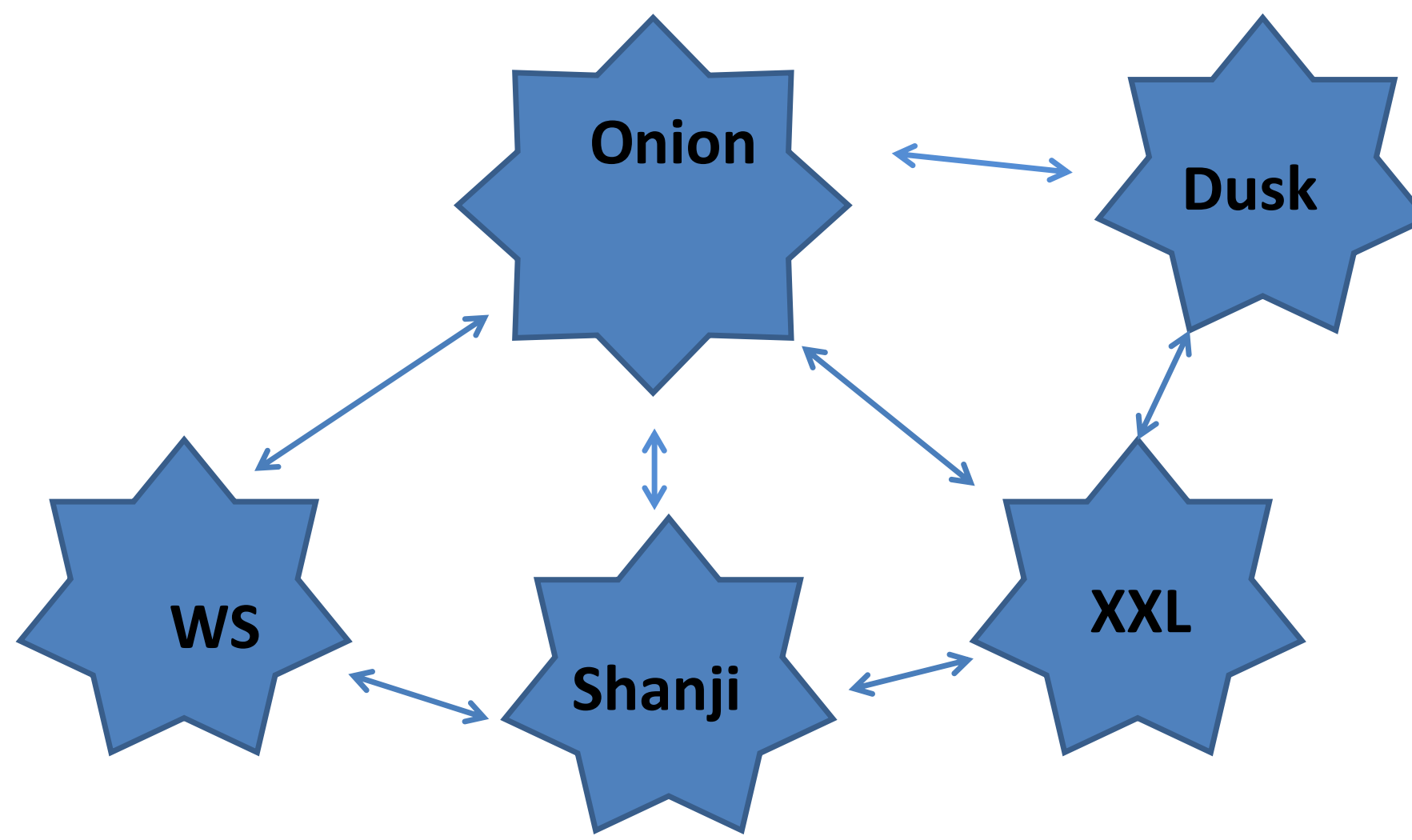

